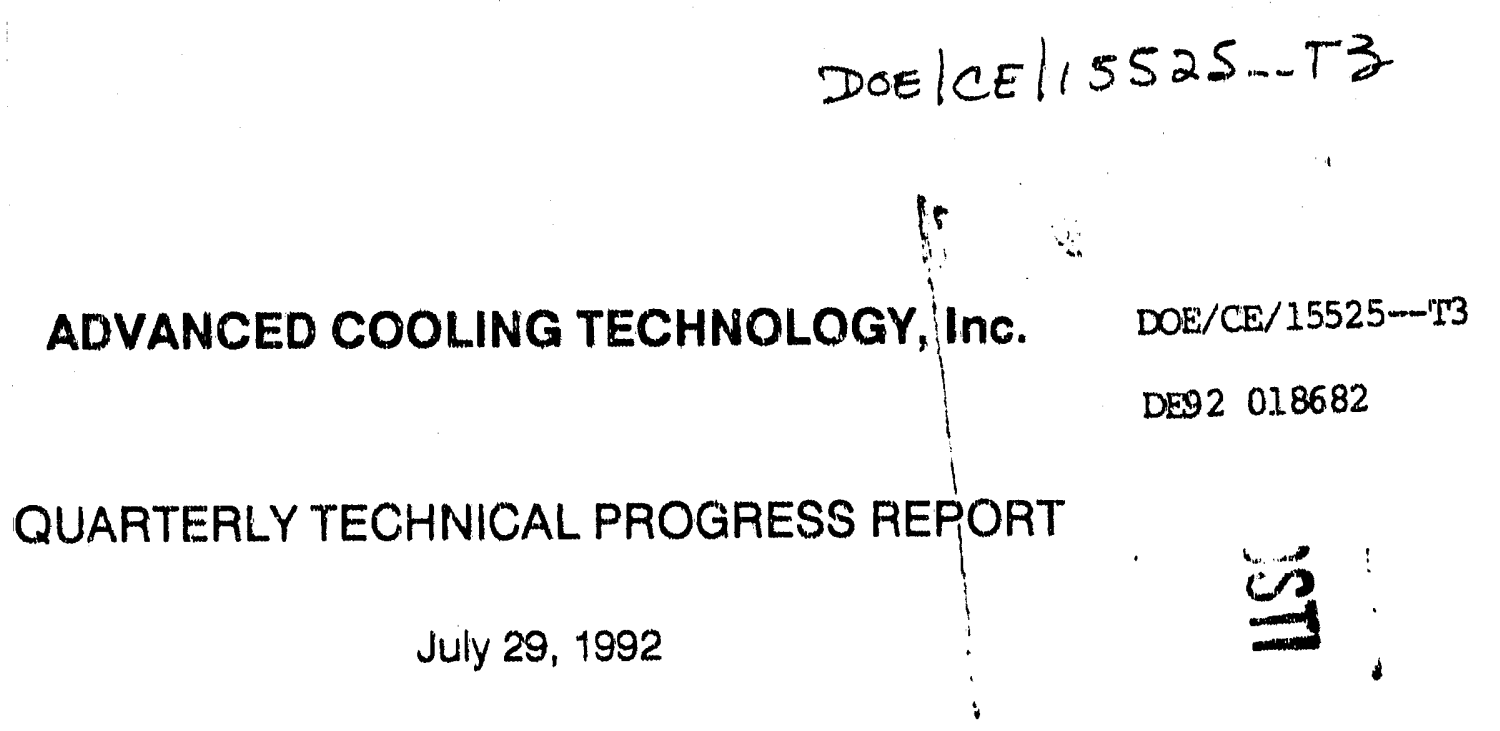

U. S. Department of Energy

Grant Project No. 01-91CE 15525

Copies to:

Mr. Elliot Levine, CE-521

U. S. Department of Energy

1000 Independence Ave., S.W.,

Washington, D. C. 20585

U. S. Department of Energy

Office of Placement \& Administration

Attn.: Bernard G. Canias, PR-322.2

1000 independence Ave., S.W.,

Washington, D. C. 20585

U. S. Department of Energy

Office of Scientific \& Technical Information

P. O. Box 62

Oak Flidge, TN 37830 


\section{PROJECT DESCRIPTION}

Advanced Cooling Technology (ACT), Inc., will perform the following tasks in order to develop an improved, more reliable and more marketable version of their ACT Evaporative Subcooling System.

1. Develop a more stable pump by reducing vibration levels.

2. Design and develop a drainage mechanism that will protect the coil.

3. Apply for Underwriters Laboratories approval and perform follow-up and coordination work to complete task to insure product is safe, within its intended applications.

4. Test invention's performance to demonstrate energy savings and long term resistance to scale and corrosion.

5. Contract with the American Refrigeration Institute to perform engineering tests under controlled laboratory conditions. Tests to incluse pressure and temperature data throughout the refrigeration cycle.

6. Organize data, and develop technical manual for helping purchasers determining energy savings and invention's merits.

7. Perform a field test in a cooperating supermarket, where utility usage can be measured on a before and after basis.

8. Submit progress and financial reports at the end of each calendar quarter. Submit a final report at the end of the grant period that summarizes the technical accomplishments and next steps to make this technology a commercially viable option. The final report will estimate the energy and other benefits of using this system. 
Essentially all of the mechanical design improvements proposed for the Evaporative Subcouler having been completed and the production of pilot quantities of the improved parts was done. An effort was made to have some of these installed in field units where difficulties have been observed in the past. Major attention was focussed during this period on the performance of controlled third party tests of the effectiveness of the unit in improving energy efficiency.

In addition, during this Quarter a second or "Continuation Patent" was granted by the U. S. Patent Office allowing much broader claims than was the case of the first patent which was granted in December, 1991.

Task No. 1

Pump Design

This task has now been completed. Tests of the improved pump in the laboratory, as reported last period, were highly successful. During this period a number of these improved units were sent to the field both on new subcooler units and also as replacement parts for old pumps which had failed in service because of vibration problems. No reports of difficulties with the new pumps have been received.

Task No. 2

Drainage Mechanism

This task has now been completed from the design standpoint. Ten subcooler units with coated coils were sent to a Florida area where the most severe corrosion problems have been encountered. Attempts will be made to follow the results of this treatment in affecting coil corrosion.

Task No. 3

Underwriters Laboratories Approval

This task has been abandoned for the reasons described in the previous Quarterly Report. 
Task No. 5

American Refrigeration institute Tests

Copies of the reports of the ARI tests performed by ETL Testing Laboratories are included herewith as Appendix $A$ (Refrigeration) and Appendix $B$ (Air Conditioning).

Refrigeration:

A Copeland 5 HP Refrigeration unit was rented and shipped to ETL. Testing Laboratories for these tests and was returned to us at their completion. The results showed that at $95^{\circ} \mathrm{F}$ and at $41 \%$ Relative Humidity, the Evaporative Subcooler increased the capacity of the system by $7.86 \%$. At $99.70 \mathrm{~F}$ and at $43 \%$ Relative Humidity, the increase was $12.48 \%$.

Air Conditioning:

A Carrier Unitary 10 Ton Air Conditioner unit which was being tested for other characteristics at ETL Testing Laboratories was made available by the Carrier Corporation for use in our Evaporative Subcooler tests. The results showed that at $99.4 \circ \mathrm{F}$ and at $43 \%$ Relative Humidity, the Evaporative Subcooler improved the Energy Efficiency Ratio (EER) of the system by $8.31 \%$.

Several considerations must be kept in mind in the interpretation of these results:

1. The ambient conditions under which the tests were carried out were rather normal summer temperatures and humidities. In many areas of the country, higher temperatures and lower humidities often prevail, both of which promote greater evaporative cooling.

2. The systems were both well "balanced", i.e., the capacities of the compressor and the conderiser were well matched. The Copeland refrigeration components were selected by our engineer to achieve this balance. The Carrier air conditioner system is described as "uritary", with components selected and assembled by the manufacturer at the factory. These considerations along with the fact that the systems were properly charged with the correct amount of refrigerant by ETL Laboratories engineers before testing means that they were operating at top efficiency for the "base-line" tests before the Evaporative Subcoolers were installed. The conclusion that can be drawn from this is that the observed 
improvements are the minimum that can be expected for installation on systems operating under these ambient conditions.

3. In contrast, however, much larger improvements are frequently obtained in field installations. If, for example, a system is unbalanced because it has an undersized condenser, the addition of a subcooler, even without any evaporative cooling, will improve the performance of the systern by increasing tho condenser capacity bringing it nearer to balance with the compressor capacity. Add the effect of evaporative cooling and much more improvement is obtained. Similarly, if a system is not properly charged with refrigerant and, as a part of the subcooler installation, the refrigerant charge is brought to the proper level, additional improvement over that attributable to evaporative subcooling may be observed. While these are not true efficiency improvements achieved by evaporative subcooling, they are real energy efficiency gains resulting from the whole process of installing an evaporative subcooler. 


\title{
APHVIX A REPORT
}

\section{ETL TESTING LABORATORIES, INC.}

INDUSTRIAL PARK

Order No. 64670-410
CORTLAND. NEW YORK 13045

Date: May 4, 1992

\author{
REPORT NO. 517055 \\ RENDERED TO \\ ADVANCED COOLING TECHYOLOGY TNC. \\ PERFORMANCE TESTS OF A \\ "ACTEC" MODEL 10 \\ EVAPORATIVE SUBCOOLER \\ (REFRIGERANT R-12)
}

General

This report gives the results of Performance Tests of an "ACTEC" Model 10 Evaporative Subcooler coupled to a "Copeland" Model CBAM0500-TFC-001 condenging unit for refrigeration.

The samples were selected and submitted by the client and received at ETL on March 18, 1992. The work was authorized by client's letter dated February 26, 1992. Testing was coordinated through Mr. Ira Marsh representing the client.

\section{Test Method}

The test was performed in general accordance with the following standards published by the American society of Heating, Refrigerating, and Air-Conditioning Engineers, Inc.

ASHRAE 41.9-88 A standard Calorimeter Test rethod for Flow Heasurement of a Volatile Refrigerant

ASHRAE 20-70 Methods of Testing for Rating Remote Mechanical-Draft Air-Cooled Refrigerant Condensers alid to the compreherisiveness of the teste, exarninations or surveye mede. No quosatlons from reports or use of ETL' name le perrivited except as expresely authorized by ETL In viriling. 


\section{Description of Test setup}

The evaporative subcooler and the refrigeration system condenging unit were installed in a temperature controlled environment. The refrigerant leaving the condensing unit was valved to go through or to bypass the "ACTEC 10" evaporative subcooler. The test system was coupled to a Secondary Refrigerant Calorimeter. Calibrated precision pressure gauges were used to determine refrigerant pressures throughout the system. Calibrated RTD's and thermocouples were used to measure refrigerant and ambient air temperatures. Refrigerant flow was determined by a turbinetype flow meter.

Calorimeter heat input was determined by a watthour transducer measuring the watt input to the evaporator heaters.

Refrigerant flowrate for the primary measurement was determined as the quotient of the heat input to the calorimeter and the enthalpy change of the refrigerant passing through it. The confirming method of the refrigerant flow was the turbine flow meter. 


\section{Description of Sample Physical and Nameplate Data}

\section{General Description of Sample}

The subcooler consisted of an aluminum finned copper heat exchanger coil, a down draft fan and a cone pump.

The refrigerant condensing system unit consisted of a compressor, condenser coil, fan and two receivers.

The refrigerant was $R-12$.

2. Nameplate Data

Subcooler

"Advanced Cooling Technology

ACTEC Evaporative subcooler

Model No. 10 serial 543

Voltage $230 \mathrm{~Hz} 60 \quad 0.4$ Amps"

Condensing Unit

"Copeland

Model CBAM-0500-TFC-001

$208 / 230$ volt $3 \mathrm{Ph} 60 \mathrm{~Hz} "$

\section{Compressor}

"Copeland

Model 9RA1-0500-TFC"

\section{Description of Tests}

\section{Conditions}

$\begin{array}{lrr}\text { Ambient, }{ }^{\circ} \mathrm{F} & 95 & 100 \\ \text { Saturation Suction, }{ }^{\circ} \mathrm{F} & -10 & -10 \\ \text { Return Gas, }{ }^{\circ} \mathrm{F} & 65 & 65\end{array}$

Test Runs 1 and 3 were with the refrigerant bypassing the evaporative subcooler.

Test Runs 2 and 4 were with the evaporative subcooler energized and supplied with city water. 


\section{Test Conditions}

Saturated suction, F

Return Gas, F

Ambient of Conderser, $F$

Results of Tests

Condenser Ambient

$$
\begin{array}{r}
\text { Air } \text { Inlet, } F \\
\text { ary-bulb } \\
\text { wet-bulb }
\end{array}
$$

Barometer, in. $\mathrm{Hg}$.

Calor meter side

Electric Input to Heaters, Whrs

REFRIGERATING CAPACITY, BTUH

Calculated Refrigerant Flow, lbs/hr

\section{Refrigerant side}

Refrigerant Temperature, F

Liquid at condenser

Liquid Entering Subcooler

Liquid Leaving subcooler

Liquid at Calorimeter

suction at calorimeter

suction at Compressor

Refrigerant pressures, PSIG

Iiquid at condenser

Liquid at calorimeter

suction at calorimeter

suction at compressor

Refrigecant Enthalpy, Btu/lb

Entering Calorimeter

Leaving Calorimeter

Difference Across Calorimenter

Refrigerant Flow Rate, lbs/hr

Electrical characteristics

Voltage, volts

Phase $A-B$

Phase $B-C$

Phase C-D

Current, amps

Phase A

Phase $B$

phase $C$

Total Power Input, watts
Test Run

\begin{tabular}{cc}
\multicolumn{2}{c}{ Test Run } \\
\hline-10 & $\frac{2}{10}$ \\
65 & -10 \\
95 & 65 \\
& 95
\end{tabular}

$95.2 \quad 95.0$

$74.7 \quad 75.1$

$28.73 \quad 28.84$

\begin{tabular}{rr}
4,584 & \multicolumn{1}{r}{4,944} \\
15,640 & 16,870 \\
283.9 & 283.9
\end{tabular}

107.5

107.0

$-$

106.5

-

83.5

101.4

82.6

61.6

61.4

65.0

65.0

173.5

173.0

172.0

171.5

6.0

6.0

4.5

4.5

31.438

26.972

86.512

86.407

55.072

59.435

278.6

277.7

230

230

230

230

230

230

13.8

13.9

15.2

15.1

14.2

14.2

3,895

3,953

checked by: My 


\section{Test Conditions}

$$
\begin{aligned}
& \text { Saturated suction, F } \\
& \text { Return Gas, F } \\
& \text { Ambient of Condenser, F }
\end{aligned}
$$

Results of Tests

Condenser Ambient

$$
\begin{gathered}
\text { Air Inlet, } \mathrm{F} \\
\text { dry-bulb } \\
\text { wet-bulb } \\
\text { Barometer, in. } \mathrm{Hg} \text {. } \\
\text { Calorimeter side }
\end{gathered}
$$

Test Run

\begin{tabular}{rr}
\hline 3 & -4 \\
\hline-10 & -10 \\
65 & 65 \\
100 & 100
\end{tabular}

99.9

99.5

78.4

79.5

28.41

28.45

$\begin{array}{rr}4,039 & 4,543 \\ 13,780 & 15,500 \\ 258.8 & 262.3\end{array}$

115.9

115.6

-

114.8

$-$

83.9

107.4

81.6

59.5

60.3

64.7

65.2

198.5

196.0

197.5

195.0

6.0

6.0

4.5

4.5

32.89 .4

27.183

86.139

86.255

53.245

59.072

254.6

254.8

230

230

230

230

230

230

13.7

13.8

14.9

14.7

14.2

14.1

3,820

3,879

checked by: hily 
(GID.

Report No. 515851

6.

Dates of Tests: April. $22-24,1992$

Report Approved by:

mark. Saquette

Mark W. Maquette, Manager

Applied Products
Tests supervised by:

Dobents. Neil

Robert J. Hill

Project Engineer

checked by: My

copy by: kn 


\section{REPORT \\ ETL TESTING LABORATORIES, INC. \\ INDUSTRIAL PARK \\ CORTLAND, NEW YORK 13045}

Order No. $64672-420$
Date: June 11, 1992

REPORT NO. 518483

RENDERED TO

ADVANCED COOLING TECHINOLOGY, INCORPORATED

PERFORMANCE TESTS

OF A "CARRIER" UNITARY AIR CONDITIONER

MODEL, 38AFC0085 CONDENSING UNIT

WITH MODEL $40 R R O O B$ BLOWER COIL

WITH AND WITHOUT AN "ACTEC" EVAPORATIVE SUBCOOLER

General

This report gives the results of performance Tests of a "Caxrier" Unitary Air Conditioner Model $38 \mathrm{AFC} 0085$ Condensing Unit with Model 40RR008 Blower Coil, with and without an "ACTEC" Evaporative subcooler manufactured by Advanced Cooling Technology, Incorporated, Lexington, Kentucky 40503.

The sample used to test the evaporative subcooler was provided by Carrier corporation.

Authorization for the tests was by client's letter dated February 26, 1992, signed by Mr. Homer S. Kyerg, President. The work was coordinated through Mr. Ira Marsh, Chief Engineer, representing the client.

The tests were conducted in accordance with ARI Standard 210/240-89, "standard For Unitary Air-Conditioning And Air-Source Heat pump Equipment," published by the Air-Conditioning and Refrigeration Institute, and ASHRAE Standaxd BNSI/ASHRAE 37-88, "Methods of Testing for Rating Unitary Air Conditioning and Heat pump Equipment," published by the American Society of Heating, Refrigerating and Aix Conditioning Engineers, Inc.

Notes: (1) The results contained herein are for technical evaluation only and are applicable only to the specific test specimen referenced herein.

(2) The tests herein reported have not been performed at the request of the Air-Conditioning and Refrigeration Institute, and use of these findings by Advanced Cooling Technology, Inc. in any advertising or other literature shall state therein that the test is not part of the ARI Certification program.

All services undertaken subject to the following general policy: Repons are submitted for exclusive use of the cliente to whom they are sddresed. Their significance to subject to the adequncy and reprecentative character of the sample

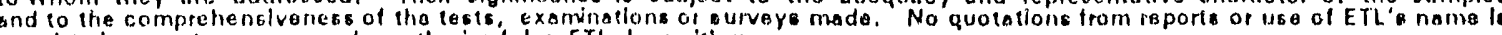
permitted except a expressly authorizod by ETL In writing. 


\section{Description of Unit, Nameplets Data, ete.}

\section{Genere1 Description of Unit}

The sample was a split-eystem alr-cooled air conditioner. The condener air w drawn through the condenser coll on three bides and discharged vertically by a $f$ fxom the top of the saction. The evaporator aje was drawn through the front openin air filters and diagonal evaporator roil, and diacharged vertically by a blower through two ppenting at the top af the section. The sections were connected by 25 f of 1-1/8-in. O.D. auction line (ingulated) and 1/2-in. O.D. Ilquid line. The refrigexant control device contained in the unit was an expansion valve.

\section{Nameplate Bets}

\section{Condensing Unit}

Model No. 38AFCO08510 Serlal No. 0792G78198

\begin{tabular}{|c|c|c|c|c|c|c|}
\hline & Qt: $y$ & Voltis AC & $\mathrm{h}$ & $\mathrm{Hz}$ & RLA & LRA \\
\hline \multirow[t]{2}{*}{ Compressor } & 1 & $2018 / 230$ & 3 & 60 & 32.5 & 183 \\
\hline & & & & & FLA & HP \\
\hline an & 2 & $208 / 230$ & 1 & 60 & 2.9 & .50 \\
\hline
\end{tabular}

Power supply $208 / 230 \mathrm{~V} 3 \mathrm{Ph} 60 \mathrm{Hx}$

R-22 Design Test Presisure High 477 Low 150

permiarible Voltage At Unit $253 \mathrm{Max} .187 \mathrm{Min}$.

Min. Circuit Amp 44.4 60 Fusa only

\section{Compressor}

Copeland

Model No. BRE2-0750-TFC-214

Serial No. $92 \mathrm{~A} 1560500015$

Customer No. GB3OTNOLOA WOL9 OLL- 128

Volts $208 / 230$ Ph $3 \quad H z 60$ LRA 183

Volts $200 / 240 \mathrm{~Hz} 50$ PrO T MO-C

\section{Condencer Fan Motox}

G.E. Hodel 5K.CP39PGH8065

$\mathrm{V} 208 / 230 \mathrm{~Hz} 60$ Ph 3 Amps 1.7

Cap $10.00 / 370$ Rot. $\rightarrow$ RPM 1050

ME. No. HC44VL603A

Blower Coil Unit

Model No. 40RR-008-530 Serial No. 1292591201

Design TeBt Pressure High 410 HP I Kw Out 0.75

Powar supply 208/230-460 Volta $3 \mathrm{Ph} 60 \mathrm{~Hz}$

I.D. Motor $230 / 460$ volts $3 \mathrm{Ph} 60 \mathrm{~Hz} 3.8 / 1.9 \mathrm{FLA}$

\section{Evaporator Blower Motor.}

Inaccessible 
Description of Unit, Nameplate Data, etc. (cont'd)

\section{Description of Coils}

Number of Coils

Fin Material

Tubing Material

style

Type of Fins

Number of Fins per Inch

Diameter of Tubing (OD), in.

Number of Tubes per Row

Center-to-Center Distance Between Tubes, in.

Number of Rows Deep

Coil Height, in.

Coil Length, in.

Face Area (Total), sq. ft.
Evaporator

1

Aluminum

Copper

Staggered

Rippled

1.3

$1 / 2$

20

$1.25 \times 1.25$

3

25.0

42.0

7.29
Condenser

1

Aluminum

Copper

Staggered

Rippled

15

$3 / 8$

32

$1.0 \times 0.866$

2

32.0

$77-1 / 2$

17.22 


\section{Results of Tests}

\section{Evaporator Side}

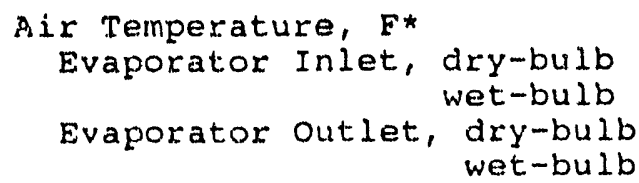

static Pressure at Unit outlet, in. W.G. Standard Air Flow, cfm

TOTAL COOLING EVAPORATOR SIDE, BLu/hr

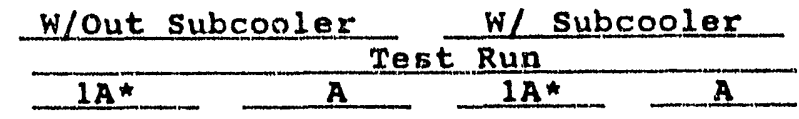

\section{Condenser side}

Air Temperature, $F$ *

Condenser Inlet, $d r y-b u l b$ wet-bulb

Condenser outlet, dry-bulb

static Pressure at Unit outlet, in. W.G. standard Air Flow, cfm

TOTAL COOLING CONDENSER SIDE, Btu/hr

$\begin{array}{cccc}99.40 & 99.50 & 99.50 & 99.30 \\ 78.80 & 78.90 & 79.50 & 79.50 \\ - & 127.30 & - & 127.90 \\ - & -0.03 & - & -0.04 \\ - & 3555 & - & 3365 \\ - & 74330 & - & 70200\end{array}$

\section{Miscellaneous}

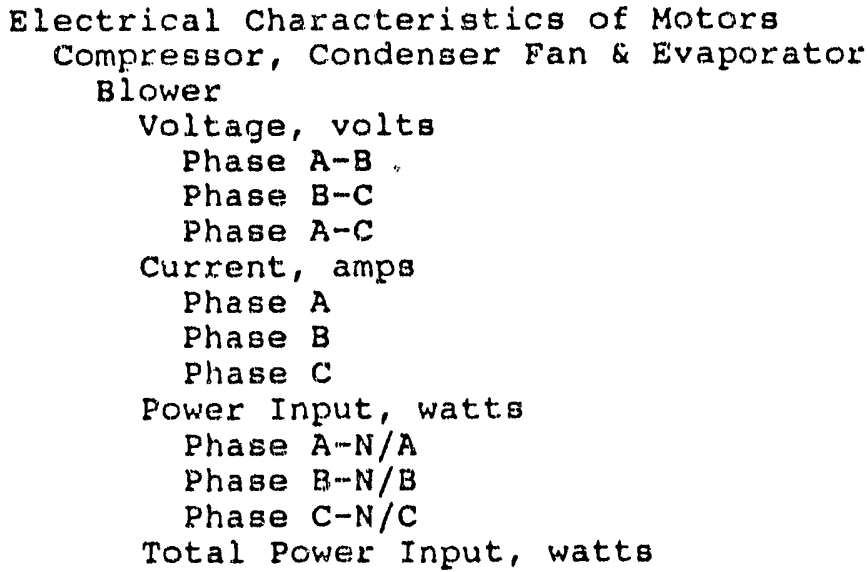

Energy Efficiency Ratio, EER

\section{Refrigerant-Circuit Temperatures, $F$}

Discharge at Compressor

Liquid at condenser

liquid at Evaporator

Suction at Evaporator

suction at Compressor

Liquid at subcooler In

Liguid at subcooler out

\section{Refrigerant-Circuit Pressures, psig}

Liquid at Condensing Unit

suction at Condensing Unit:

\section{5}

29.5

30.3

30.2

31.4

31.5

32.5

32.4

29.8

29.6

30.6

30.5

3330

3490

3210

100.30
3340

3500

3200

10040

7.46

\section{0}

3650

3300 10450
3470

3640

3300

10410

\subsection{8}

Note: Air temperatures are recorded to $0.05^{\circ} \mathrm{F}$; this value is estimated and is valid only for obtaining temperature differentials as may be required to determine enthalpies. 


\section{Remarks}

In the absence of specified requirements, no conclusion has been drawn. The test results are furnished for the client's information and evaluation.

Dates of Tests: May 21-27, 1992

Report Approved by:

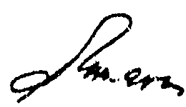

Reginaldo I. Romero

Program Administrator
Test supervised by:

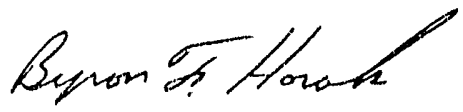

Byron F. Horak, Manager Unitary Products

Copied by: mb 

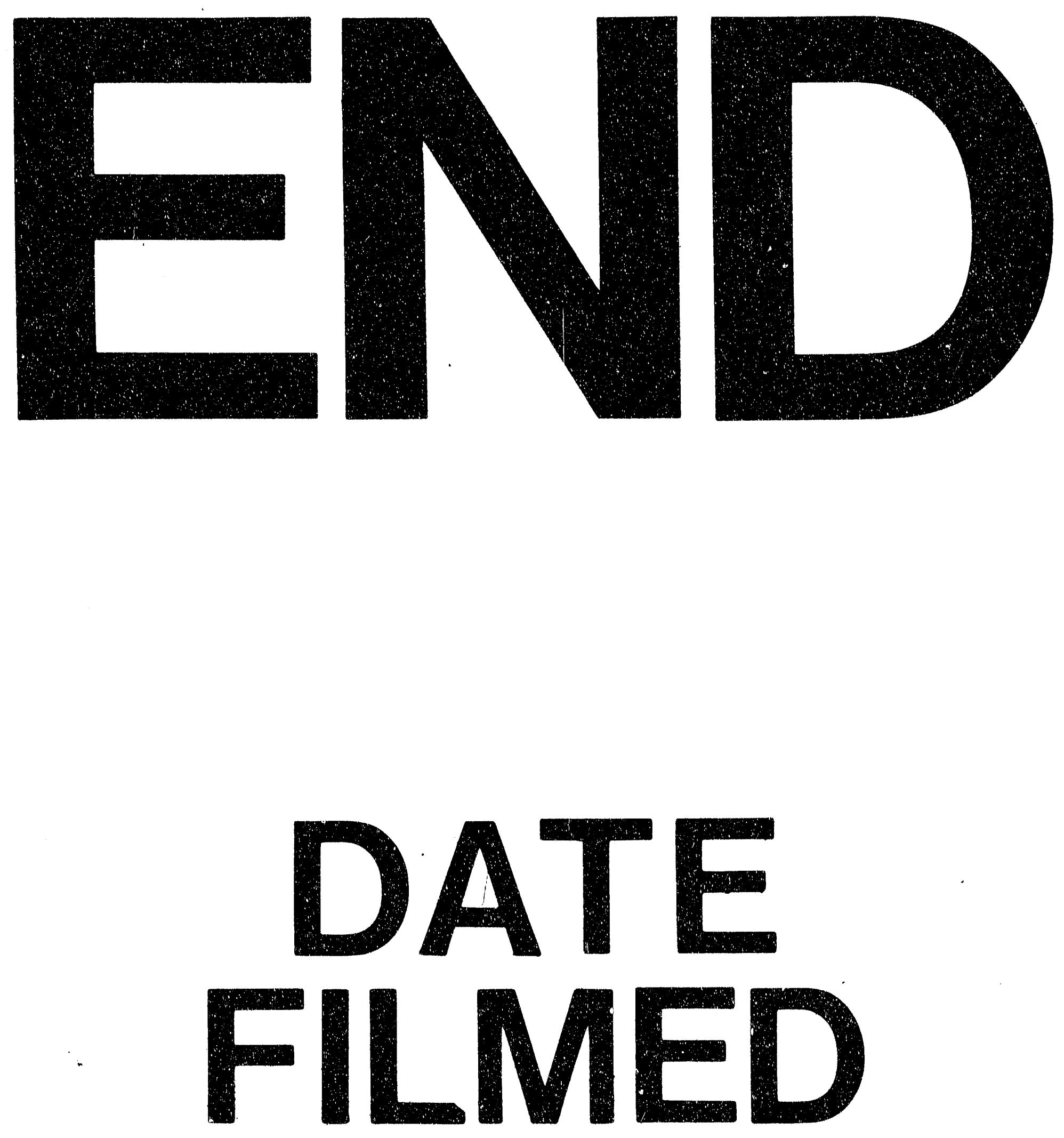

$\exists$

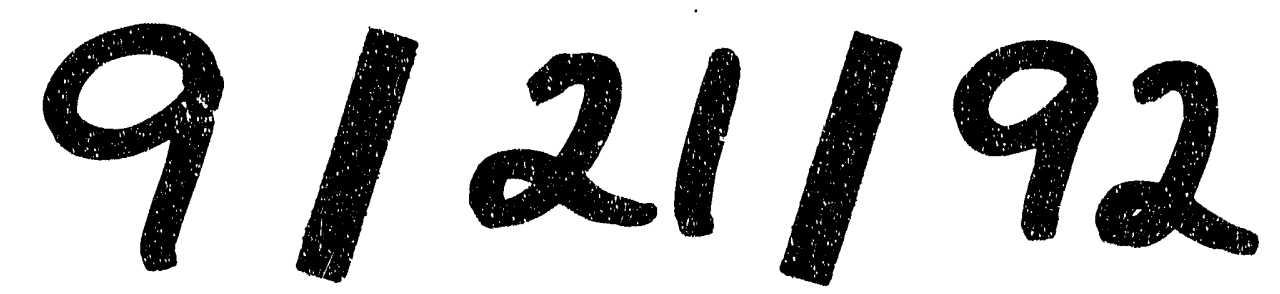


